\title{
Article \\ Improvements in the Water Retention Characteristics and Thermophysical Parameters of Backfill Material in Ground Source Heat Pumps by a Molecular Sieve
}

\author{
Tingting Luo ${ }^{1,2} \mathbb{D}$, Peng Pei ${ }^{1, *}$, Yixia Chen ${ }^{1}$, Dingyi Hao ${ }^{3}$ and Chen Wang ${ }^{1}$ \\ 1 Mining College, Guizhou University, Guiyang 550025, China; tingtingluo2022@163.com (T.L.); \\ yixiachen0118@163.com (Y.C.); cwang@gzu.edu.cn (C.W.) \\ 2 College of Materials and Metallurgy, Guizhou University, Guiyang 550025, China \\ 3 Key Laboratory of Deep Coal Resource Mining, Ministry of Education, China University of Mining and \\ Technology, Xuzhou 221116, China; hdy@cumt.edu.cn \\ * Correspondence: ppei@gzu.edu.cn
}

check for

updates

Citation: Luo, T.; Pei, P.; Chen, Y.;

Hao, D.; Wang, C. Improvements in the Water Retention Characteristics and Thermophysical Parameters of Backfill Material in Ground Source Heat Pumps by a Molecular Sieve. Energies 2022, 15, 1801. https:// doi.org/10.3390/en15051801

Academic Editor: Adrián

Mota Babiloni

Received: 11 January 2022

Accepted: 22 February 2022

Published: 28 February 2022

Publisher's Note: MDPI stays neutral with regard to jurisdictional claims in published maps and institutional affiliations.

Copyright: (c) 2022 by the authors. Licensee MDPI, Basel, Switzerland. This article is an open access article distributed under the terms and conditions of the Creative Commons Attribution (CC BY) license (https:/ / creativecommons.org/licenses/by/ $4.0 /)$.

\begin{abstract}
The thermophysical properties of backfill material (BM) in a heat exchange borehole significantly influence the heat exchange effect of ground source heat pumps (GSHPs). Several treatments such as compaction and adding bentonite, cement, and fine sands are often used to improve the thermophysical properties. In this study, a 3A molecular sieve (3A-MS), a type of porous material, was added to the BM to enhance its water maintaining capacity. Three types of backfill materials with different additive contents, named as BM-0, BM-1, and BM-2, were examined. The variation of the BM properties such as the soil-water characteristic curve (SWCC), thermal conductivity, specific heat capacity, and thermal diffusivity with the groundwater content were investigated through a series of experiments and simulations. A scanning electron microscope (SEM), an energy dispersive spectrometer (EDS), and the BET method for specific surface area pore size analysis were used to characterize the material. The results indicated that the specific heat capacity improved with the water content whereas the thermal conductivity and thermal diffusivity decreased with the water content. The variation of the buried pipe outlet temperature with the change of the thermal physical parameters of the BM were researched by a numerical simulation and theoretical calculations; the results showed that BM-2 could raise the heat transfer rate per meter by $45.9 \%$ in summer and $118.4 \%$ in winter compared with the backfill materials without groundwater (NW). The research results provide theoretical support for the improvement of BM for ground source heat pump projects where abundant groundwater is available.
\end{abstract}

Keywords: heat exchange borehole; 3A molecular sieve; backfill material; thermophysical properties; soil-water characteristic curve

\section{Introduction}

Shallow geothermal energy is one of the most promising energy resources in China, given its unlimited distribution and recyclability [1,2]. However, due to the effect of hydrogeology, porosity, and other factors of rock and soil materials, there are many restrictions to its practical design, construction, and operation [3]. Common issues with GSHPs include a thermal imbalance, the depletion of the heat exchange capacity of the borehole, and a decrease in the system efficiency. As the direct contact medium between the U pipe and the stratum, the backfill material (BM) in the heat exchange borehole determines the heat exchange performance between the buried pipe and the surrounding rock and soil, and prevents the penetration of the surface water into the ground through the heat exchange borehole [4,5]. There are two approaches to enhance the ability of the thermal transfer for backfill materials. On the one hand, increasing the thermal conductivity is the common way to acquire a higher heat transfer capacity. Kamal [6] demonstrated that the length of 
a U pipe could be decreased by $20 \%$ with wet sand-bentonite compared with dry sandbentonite. Rong et al. [7] applied an iron tailing to BM, and the performance of GSHPs was improved with the increase in the thermal conductivity of the BM. Fabien et al. [8] proved that the thermal conductivity of the grouts was intensified with the addition of bentonite-graphite composites. On the other hand, the specific heat capacity can be used to improve the heat storage capacity of the backfill material and alleviate the problem of a thermal imbalance. Zhang et al. [9] proved that adding a phase change material to the backfill body could increase the heat storage capacity; the average increment was $155.2 \mathrm{~kJ}$ within $10 \mathrm{~h}$ compared with an ordinary backfill body. The study of Yang [10] showed that increasing the proportion of the phase change backfill materials could significantly increase the heat exchange of the borehole and improve the heat storage capacity. Li et al. [11] simulated a heat transfer process and the results presented that a shape-stabilized phase change backfill material could obtain a heat exchange about 1.37 times of a crushed stone concrete backfill material.

One should keep in mind that heat is transferred from distant geological formations to the U pipe in the borehole; along this transfer process, the heat resistance of distant formations, nearby rock and soil, and the backfill material in the borehole as well as the $\mathrm{U}$ pipe are arrayed in a series. As the thermal resistance of geological formations cannot be artificially reduced, decreasing only one of the thermal resistances such as that of the backfill material would not significantly boost the heat flow. It might even result in a heat imbalance in the borehole as the excess heat cannot be diffused to the surrounding stratum as it is limited by the thermal resistance of the surrounding rock and soil. Therefore, increasing the heat capacity of a borehole to avoid a thermal imbalance becomes another option for researchers. Although the use of phase change materials can increase the heat capacity of the material, the mechanical stability of the heat exchange hole will be affected after multiple phase change cycles [12]. It is important to develop a type of BM with a high heat capacity without sacrificing the mechanical properties.

The current backfill technology requires that the BM should be compacted as much as possible to reduce the increase of the thermal resistance caused by air-filling pores [13]. However, the moisture in the pores of BM can theoretically elevate the specific heat capacity, hence improving the heat storage capacity of the whole heat exchange borehole [12]. Most previous studies have focused on improving the thermal conductivity of BM particles rather than improving the water-holding capacity of BM [14,15]. It has been suggested that the heat storage capacity of a heat exchange borehole can be strengthened by elevating the water content of the BM to delay a heat imbalance [16]. As BM is the heat exchange medium contacting the $U$ pipe, its temperature fluctuation would be lessened during the absorbing or releasing of heat when its water content increases. Furthermore, the reduced temperature fluctuation is of benefit to control the outlet water temperature of the buried pipe and improve the techno-economic parameters of the GSHP system [17]. Nevertheless, the mechanism of the influence of groundwater seepage on the heat exchange capacity of rock and soil in groundwater areas has not been deeply analyzed.

A 3A molecular sieve (3A-MS) is a material with a large number of uniform pores and orderly arranged holes in its internal structure, giving it an intensive polarity and coulomb field [18]. Therefore, it has a high adsorption capacity for polar molecules such as water. Molecular sieves with different pore sizes can sieve different particles and the adsorption properties to the surrounding water can be adjusted by choosing different types of molecular sieves. Due to its excellent performance and affordable price, a 3A-MS has been widely used in catalysis, adsorption, ion exchange, and other fields [19-21]. However, it has not been used as a water adsorption material in the heat exchange borehole of GSHPs. In this paper, the original sands-which have been used as BM in practice-were sampled from a ground-coupled heat pump project site and an experimental platform was built to investigate the hydraulic characteristics of $\mathrm{BM}$; the $\mathrm{BM}$ of the original sands was treated by a classification and a 3A-MS was filled into the BM as an active additive. Following the geotechnical test standard, the thermal and physical parameters of the BM were analyzed. 
Through a numerical analysis, the benefits of a 3A-MS additive to the operation of the ground-coupled heat pump were studied.

\section{Experiment}

\subsection{Geological Conditions}

The BM used in this study was collected from the construction site of a high-rise residential GSHP project in Guiyang city in southwest China (Figure 1). The main component of the heat exchange borehole BM was dolomite drill cuttings, also called backfilling with original sands. There was abundant groundwater and the water table was stable. The main water source originated from atmospheric precipitation and groundwater seepage [22]. There were also many faults, fractures, joints, and fissures underground below the depth of $200 \mathrm{~m}$. The heat exchange boreholes were $120 \mathrm{~m}$ deep. The shallow formation was located in a constant temperature zone and the average formation temperature was $289.15 \mathrm{~K}$.

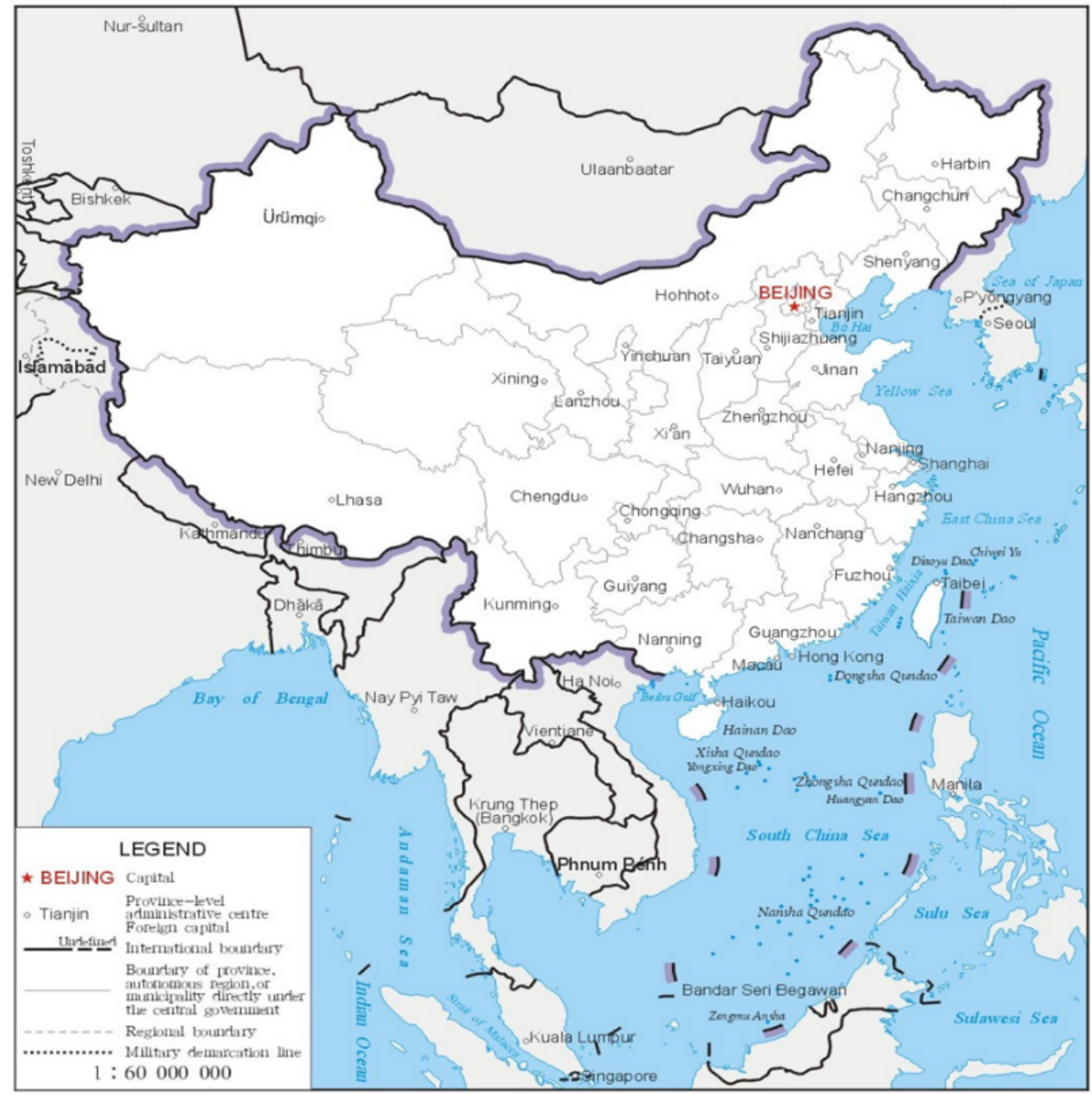

Figure 1. Location of the study aera; Drawing approval number: GS [2019]1652; Producer: Ministry of Natural Resources of China [23].

\subsection{Sample Preparation}

1. The backfill sands collected from the GSHP site were classified and the classified BM and $3 \mathrm{~A}-\mathrm{MS}$ were ground for $1 \mathrm{~min}$.

2. The ground backfill sands were separated with a sieving device. The sieving result is shown in Table 2.

3. The sieved samples were dried in a vacuum oven for $24 \mathrm{~h}$.

4. The 3A-MS and ground sands were weighed on an electronic scale.

5. The weighed 3A-MS and ground sands were mixed in a proportion in a beaker. 
6. The soil-water characteristic curve (SWCC) of the samples with an added 3A-MS of $0 \%, 5 \%$, and $10 \%$ were tested; correspondingly, the treated BMs were named BM-0, BM-1, and BM-2.

\subsection{Experimental Methods}

\subsubsection{Test of the SWCC}

The interconnected small pores in the BM of a heat exchange borehole can be regarded as capillaries with different shapes and diameters. An unsaturated zone is formed above the water table due to the effect of capillary pressure. The capillary water is lifted to a height above the free water surface because of the interface tension, which is described by Equations (1) and (2) below [24]:

$$
\begin{gathered}
\pi r^{2} h_{\mathrm{c}} \gamma_{\mathrm{w}} \mathrm{g}=2 \pi r T \cos \alpha \\
h_{\mathrm{c}}=\frac{2 T \cos \alpha}{r \mathrm{~g} \gamma_{\mathrm{w}}}
\end{gathered}
$$

where $T$ is the tension of water film, $\mathrm{N} / \mathrm{m}^{2} ; r$ is the capillary radius in the soil, $\mathrm{m} ; \gamma_{\mathrm{w}}$ is the bulk density of the water, $\mathrm{kg} / \mathrm{m}^{3} ; \alpha$ is the direction angle; $h_{\mathrm{c}}$ is the capillary water rising height or soil suction, $\mathrm{m}$; and $\mathrm{g}$ is the acceleration of gravity, $\mathrm{N} / \mathrm{kg}$.

Capillary pressure plays a vital role in the study of the hydraulic characteristics of BM, particularly capillary suction [25]. An SWCC is generally plotted by measuring the soil suction and the corresponding water content at a balance status. The measurement methods of the suction of unsaturated soil include the pressure plate meter method, centrifuge method, and filter paper method [26].

Among these methods, filter paper with porous media is used in the filter paper method as a sensor to contact the unsaturated soil. The moisture between the filter paper and the soil sample migrates in the form of liquid water when the filter paper is in contact with the soil sample in a sealed container. The suction between the soil and filter paper is equivalent when a thermodynamic balance is reached and the corresponding matrix suction of the soil is calculated by an empirical equation. The water content $\left(w_{\mathrm{fp}}\right)$ of the filter paper at an equilibrium can be calculated by the mass of the filter paper before and after the test. Whatman No. 42 or double circle No. 203 filter papers are often used in testing soil suction. The calculation equation of soil suction $(s)$ and the filter paper moisture content $\left(w_{\mathrm{fp}}\right)$ is shown in Formula (3) [27]:

$$
\operatorname{lgs}=\left\{\begin{array}{l}
4.947-0.0673 w_{\mathrm{fp}}, w_{\mathrm{fp}} \leq 0.47 \\
2.909-0.0229 w_{\mathrm{fp}}, w_{\mathrm{fp}}>0.47
\end{array}\right.
$$

\subsubsection{Thermophysical Properties}

The thermal properties of BM mainly include the thermal conductivity $(k)$, specific heat capacity $(C)$, and thermal diffusivity $(D)$. Due to its strong water adsorptivity, a 3AMS increases the water content of $\mathrm{BM}$, hence influencing its thermal properties. In this paper, the BM was regarded as a composite material and its thermophysical properties were calculated by the three-phase volumetric fraction method [28,29]. The volumetric fraction of water in BMs with different 3A-MS additive amounts was calculated by a measured SWCC.

\section{Experimental Results}

\subsection{Physical Properties and Composition}

The physical properties of the two materials are shown in Table 1. According to the chart of X-ray diffraction (XRD), the original sands collected from the site consisted of dolomite, calcite, and quartz. The 3A-MS comprised faujasite, zeolite, dolomite, and sodium aluminosilicate (Figure 2). 
Table 1. Basic parameters of the materials.

\begin{tabular}{|c|c|c|c|c|}
\hline Parameters & $\begin{array}{l}\text { Ground Sand } \\
\text { (Solid Particles) }\end{array}$ & $\begin{array}{c}\text { 3A Molecular } \\
\text { Sieve (Solid } \\
\text { Particles) }\end{array}$ & Water & Air \\
\hline Density & $1700 \mathrm{~kg} \cdot \mathrm{m}^{-3}$ & $720 \mathrm{~kg} \cdot \mathrm{m}^{-3}$ & $1000 \mathrm{~kg} \cdot \mathrm{m}^{-3}$ & $1.29 \mathrm{~kg} \cdot \mathrm{m}^{-3}$ \\
\hline $\begin{array}{c}\text { Thermal } \\
\text { conductivity }\end{array}$ & $3.24 \mathrm{~W} \cdot \mathrm{m}^{-1} \cdot \mathrm{K}^{-1}$ & $0.22 \mathrm{~W} \cdot \mathrm{m}^{-1} \cdot \mathrm{K}^{-1}$ & $0.594 \mathrm{~W} \cdot \mathrm{m}^{-1} \cdot \mathrm{K}^{-1}$ & $0.026 \mathrm{~W} \cdot \mathrm{m}^{-1} \cdot \mathrm{K}^{-1}$ \\
\hline $\begin{array}{l}\text { Specific heat } \\
\text { capacity }\end{array}$ & $1360 \mathrm{~kJ} \cdot \mathrm{m}^{-3} \cdot \mathrm{K}^{-1}$ & $680 \mathrm{~kJ} \cdot \mathrm{m}^{-3} \cdot \mathrm{K}^{-1}$ & $4186.8 \mathrm{~kJ} \cdot \mathrm{m}^{-3} \cdot \mathrm{K}^{-1}$ & $1.4 \mathrm{~kJ} \cdot \mathrm{m}^{-3} \cdot \mathrm{K}^{-1}$ \\
\hline $\begin{array}{l}\text { Water storage } \\
\text { capacity }\end{array}$ & Ordinary & Strong & / & / \\
\hline
\end{tabular}

Note: ground sands were the samples after being crushed, sieved, and dried after the drilling cuttings were taken from the project site.
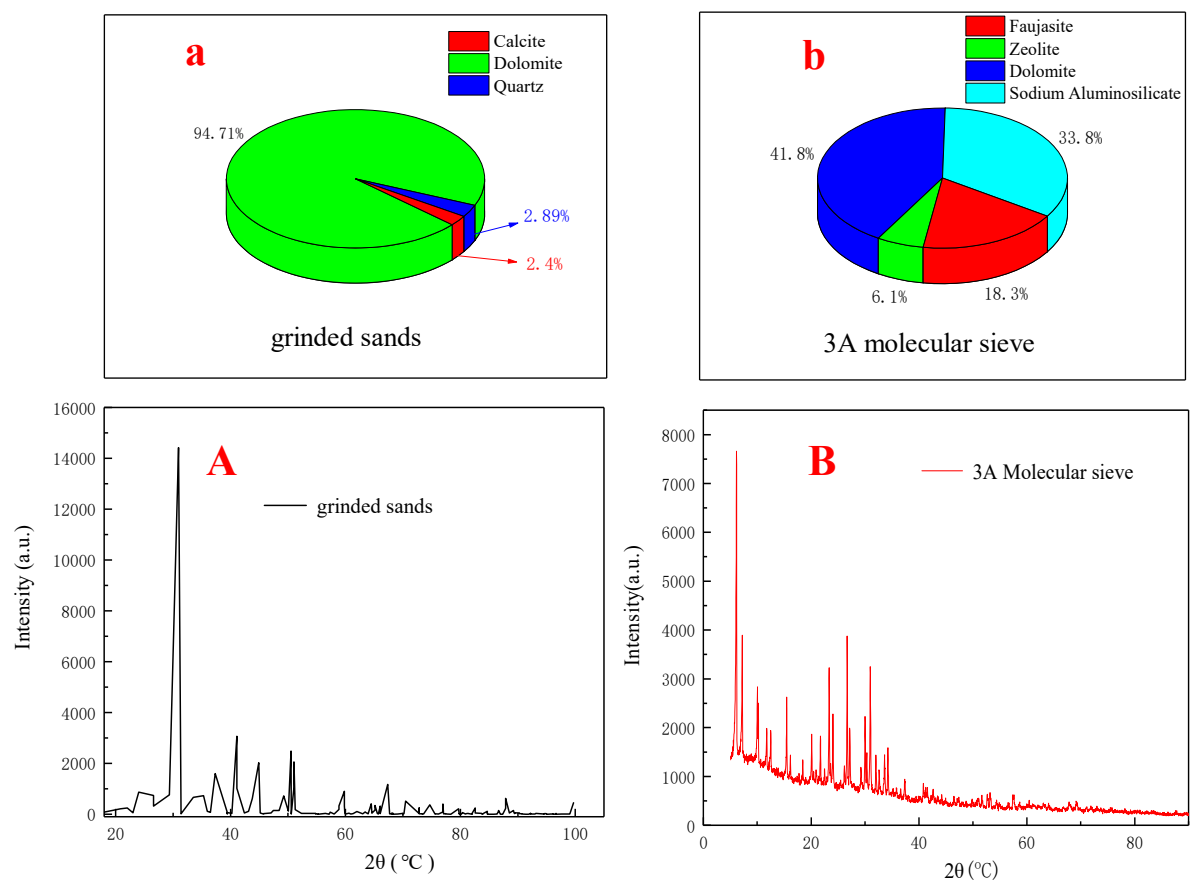

Figure 2. Charts of the XRD and main ingredients.(a) Composition of grinded sand; (b) Composition of [3A-MS].

\subsection{Sieving Curve}

A sieving curve was used to classify the particle size of the material. In this experiment, the particle size of the 3A-MS was smaller than that of the ground sand sample (Table 2).

Table 2. Mass percentage of sieving.

\begin{tabular}{cccc}
\hline Less than a Certain Particle Size (mm) & BM-0 (\%) & BM-1 (\%) & BM-2 (\%) \\
\hline 1 & 98.44 & 95.36 & 93.24 \\
0.6 & 78.95 & 70.6 & 63.2 \\
0.425 & 63.9 & 63.9 & 56.41 \\
0.25 & 13.14 & 11.65 & 9.36 \\
0.18 & 4.39 & 3.12 & 4.2 \\
0.15 & 3.89 & 2.63 & 1.63 \\
\hline
\end{tabular}




\subsection{Soil-Water Characteristic Curve (SWCC)}

The V-G model is a model developed by Van Genuchten et al. [30] in 1980. The soil-water characteristic curve model was proposed on the basis of the model formula:

$$
\theta=\theta_{\mathrm{r}}+\frac{\theta_{\mathrm{s}}-\theta_{\mathrm{r}}}{\left[1+(\partial \mathrm{g} h)^{n}\right]^{m}}
$$

where $\theta$ is the water content of the soil, $\mathrm{m}^{3} \cdot \mathrm{m}^{-3} ; \theta_{\mathrm{s}}$ is the saturated water content, $\mathrm{m}^{3} \cdot \mathrm{m}^{-3}$; $\theta_{\mathrm{r}}$ is the residual moisture content, $\mathrm{m}^{3} \cdot \mathrm{m}^{-3} ; h$ is the soil suction, $\mathrm{m} ; \alpha$ is the reciprocal of soil air intake; $n$ indicates the steepness of the curve; and $m=11 / n$.

The water content measured by filter paper method and the calculated soil suction were exported to fit the residual moisture content $\left(\theta_{r}\right)$, saturated water content $\left(\theta_{s}\right)$, and the parameters $\alpha, n$, and $m$, as shown in Table 3. The curve of the water content versus the distance from the water table was generated (Figure 3A) and the correlation coefficient $\mathrm{R}^{2}$ was over 0.95 . The water content of the BM dropped sharply near the water table and maintained a balance subsequently. When the content of the 3A-MS was $10 \%$, the surface tension and capillary water of the BM increased, indicating that BM-2 had a better water-holding property (Table 3).

Table 3. Parameters of the soil-water characteristic curves.

\begin{tabular}{cccc}
\hline Parameters & BM-0 & BM-1 & BM-2 \\
\hline$\theta_{\mathrm{r}}$ & 0.065 & 0.045 & 0.078 \\
$\theta_{\mathrm{s}}$ & 0.41 & 0.43 & 0.49 \\
$\alpha$ & 0.075 & 0.145 & 0.036 \\
$n$ & 1.89 & 2.68 & 1.56 \\
$m$ & 0.4709 & 0.6269 & 0.3591 \\
$\mathrm{R}^{2}$ & 0.998 & 0.984 & 0.975 \\
\hline
\end{tabular}
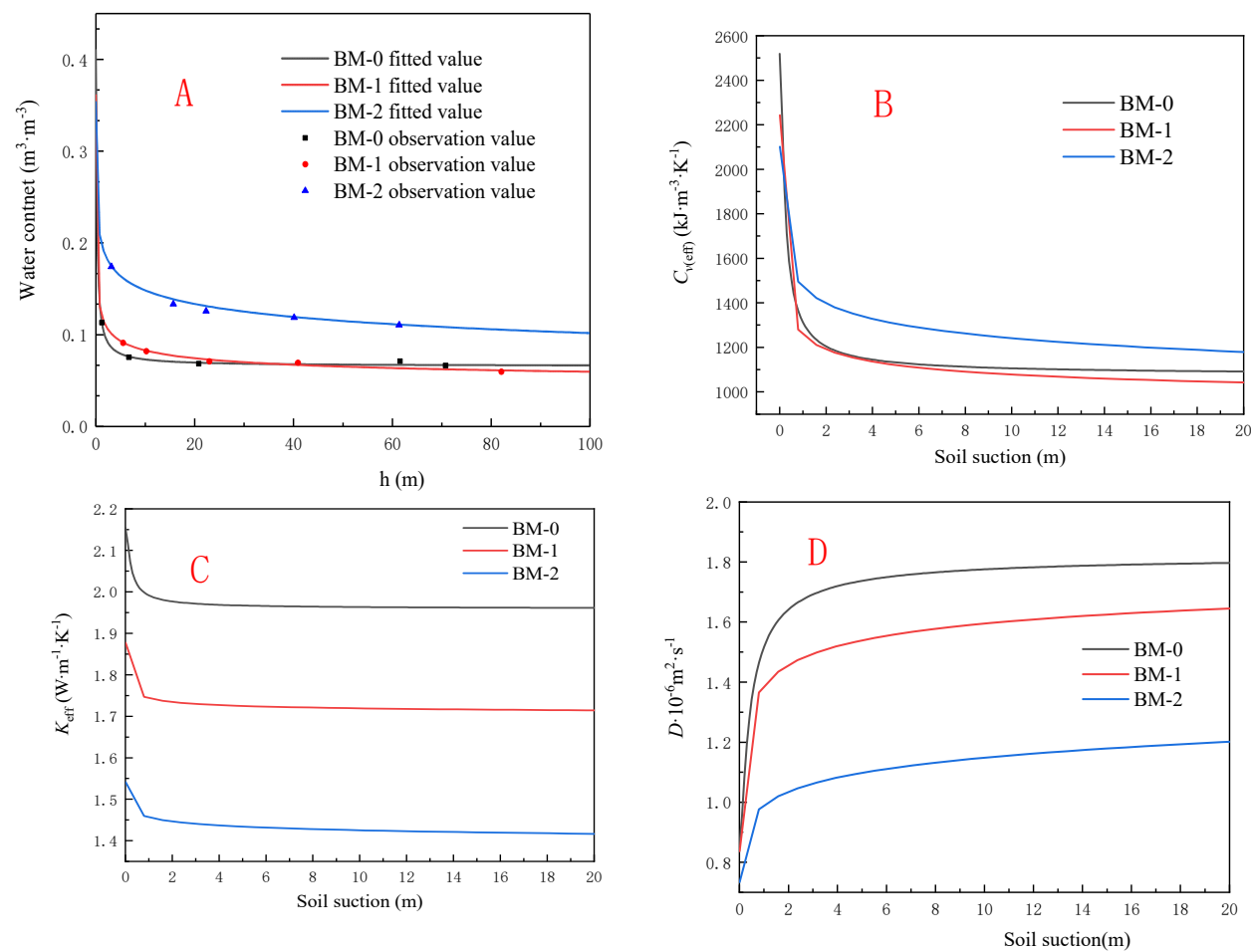

Figure 3. SWCCs and relative thermal properties. (A) Soil water characteristic curve; (B) Specific heat capacity; (C) Thermal conductivity; (D) Thermal diffusivity. (A) was obtained by data fitting; (B-D) were calculated. 


\subsection{Thermal Properties}

$\mathrm{BM}$ is composed of gas, liquids, and solids. The depth of the water table was set at $20 \mathrm{~m}$ below the surface. As shown in Figure 3B, the order of the average specific heat capacity was BM-2 > BM-0 > BM-1. As shown in Figure 3C, the thermal conductivity of each material rose as the water content increased as the water replaced the gas in the pores. However, because the lifted groundwater could be regarded as non-flowing capillary water, the heat transfer between the groundwater and BM was mainly heat conduction rather than heat convection and the thermal conductivity of the BM after adding the molecular sieve was weakened compared with BM-0. As the specific heat capacity dropped more sharply than the heat conductivity, the thermal diffusivity increased with the soil suction, as shown in Figure 3D.

\subsection{Specific Surface Area and Pore Size Test}

Through a specific surface area pore diameter analyzer, the BJH method was used to test and analyze the pore size of the BM; the test results are shown in Figure 4 . The adsorption capacity of BM-1 and BM-2 were 1.25 times and 2.43 times greater than BM0 , respectively. The desorption calculations were 1.67 and 3.2 times greater than BM-0, respectively. The specific surface area refers to the total surface area of the particles per unit in volume or mass. As can be seen from Figure $4 B$, the BET surface area, Langmuir surface area, and outer surface area of BM-1 were 1.14, 1.23, and 1 times greater than BM-0, respectively; the BET surface area, Langmuir surface area, and outer surface area of BM-2 were 2.23, 1.78, and 1.45 times greater than BM-0, respectively. The increase in the adsorption capacity and each surface area indicated that the pore volume of the BM increased by adding a 3A-MS so the material could hold more water as well as achieve the effect of water locking. The specific heat capacity of the BM improved due to the high specific heat capacity of water.
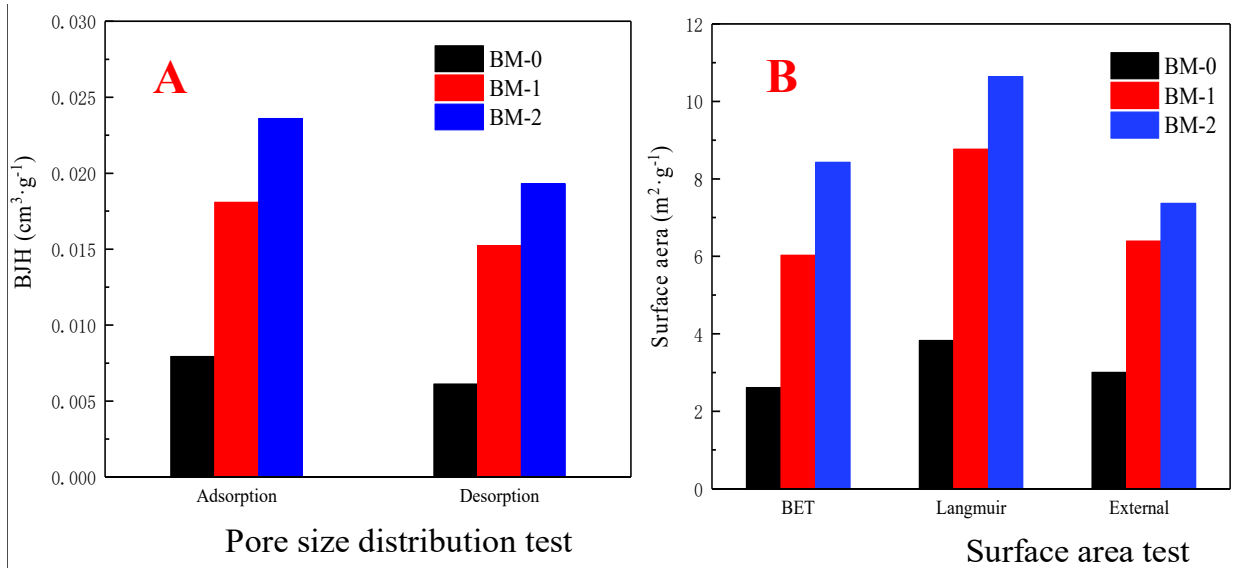

Figure 4. Charts of the porous media analysis. (A) Pore size distribution test; (B) Surface area test.

\subsection{Elemental Energy Spectrum Analysis}

An elemental energy spectrum analysis is mainly used to analyze the element composition and content of samples. In this paper, BM-0 and BM-2 were selected for an element test. The results are shown in Figure 5. Zn and $\mathrm{Zr}$ elements were brought by the addition of a molecular sieve and the mass content of $\mathrm{Al}, \mathrm{Mg}, \mathrm{Si}$, and $\mathrm{K}$ elements also increased, which indicated that those metal elements of the 3A-MS had no pollution effect on the groundwater. To conclude, the 3A-MS could be judged to be a non-toxic and harmless material from the perspective of environmental protection and, therefore, suitable for BM in heat exchange boreholes of GSHPs. 

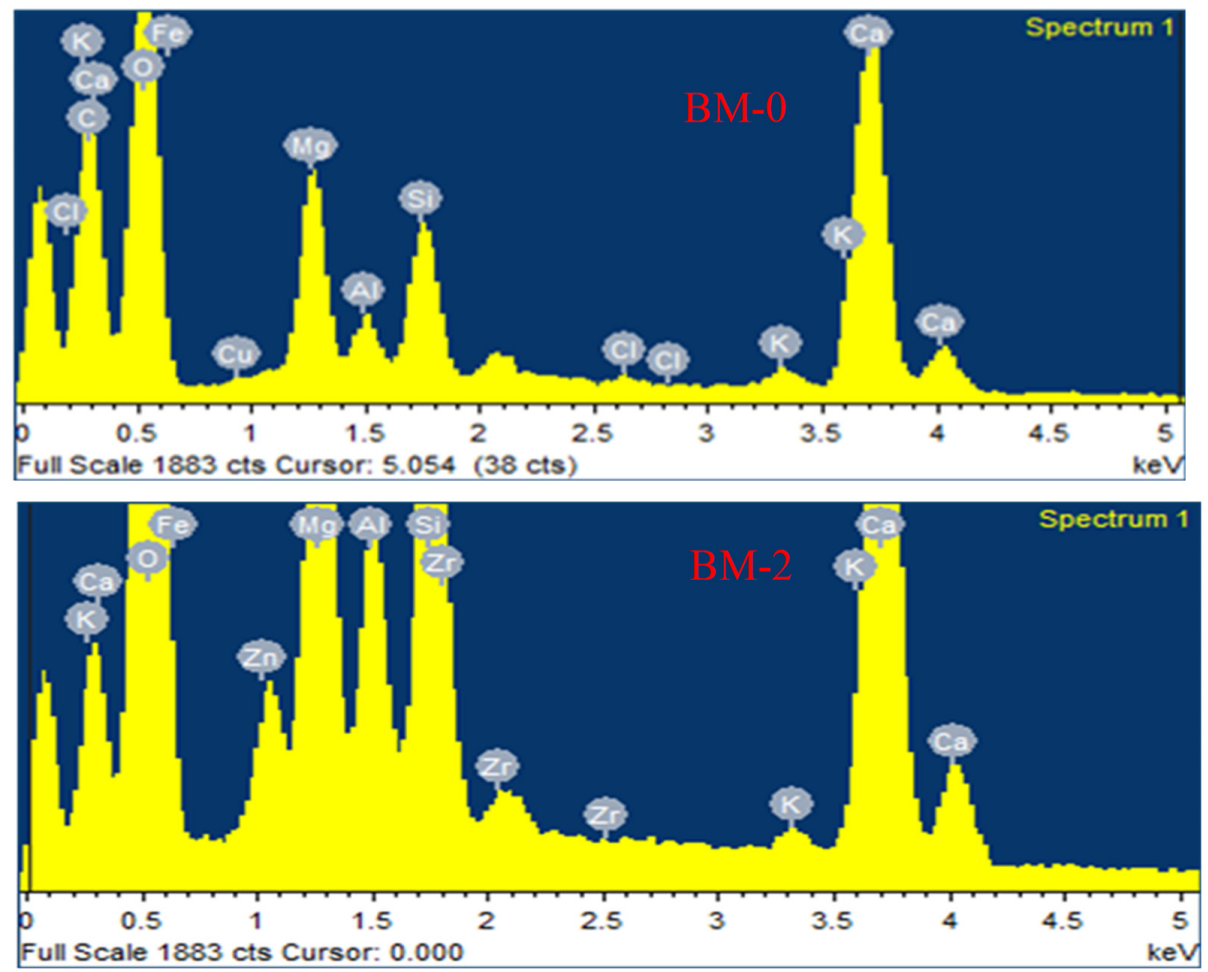

Figure 5. Energy dispersive spectrometry of BM-0 and BM-2.

\subsection{Scanning Electron Microscope}

The SEM results of the pore size distribution and SWCCs were consistent. The BMs with a 3A-MS and without a 3A-MS were separately analyzed by a scanning electron microscope. The scanning images of BM-0 and BM-2 at 100, 2000, and 5000 magnification, respectively, are shown in Figure 6. It can be seen from Figure 6a that the internal structure of the ground sand was a type of porous structure. After adding a molecular sieve, the internal pores were filled by the 3A-MS and the porosity decreased. From the higher magnification image, the small round particles closely arranged were regarded as a 3A-MS. From the pores shown in Figure 6c, the internal surface area of the solid framework drilled into the pore by the 3A-MS increased and the hydrophilicity of the 3A-MS could maintain water in the pores.

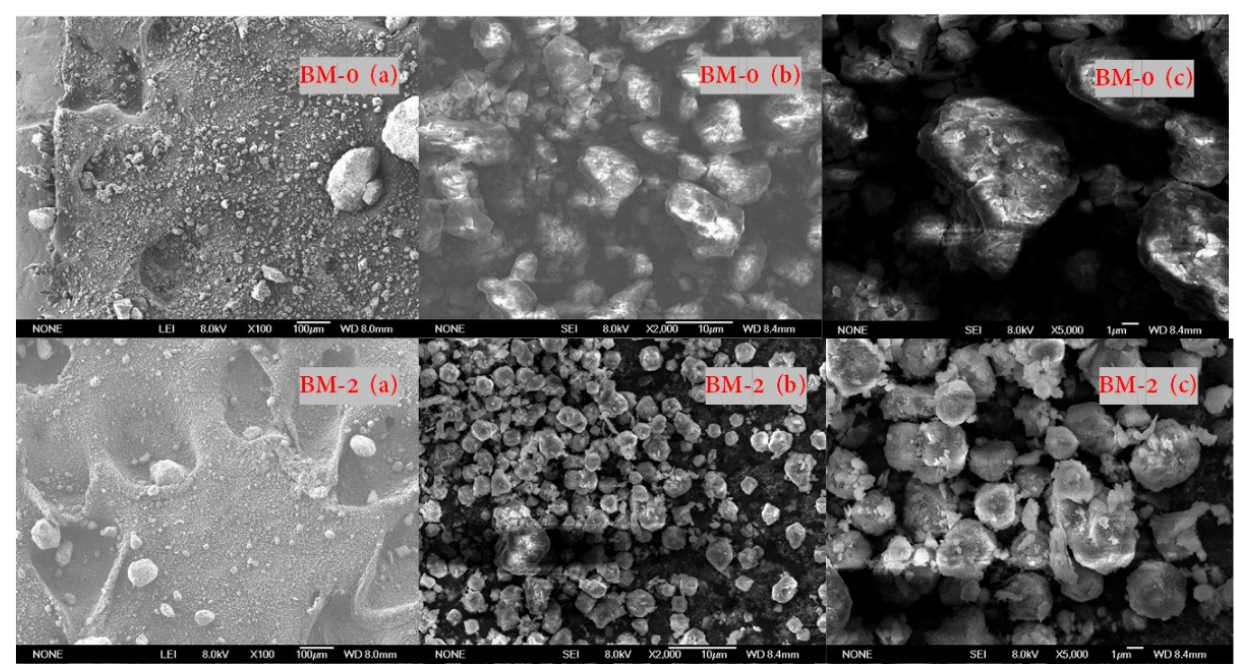

Figure 6. Charts of SEM of BM-0 and BM-2. (a) Size of $100 \mu \mathrm{m}$; (b) Size of $10 \mu \mathrm{m}$; (c) Size of $1 \mu \mathrm{m}$. 


\section{Numerical Simulation and Analysis}

The heat transfer performance of a borehole with BM-0, BM-1, and BM-2 was simulated. The cooling period in summer was three months (June to August) and the heating period in winter was four months (November to February of the subsequent year). A shutdown period of five months existed between the heating and cooling periods. The GSHP was assumed to operate for $24 \mathrm{~h}$ per day. The temperatures of the groundwater and the average temperature of the rock mass were $288.15 \mathrm{~K}$ and $289.15 \mathrm{~K}$, respectively. The baseline backfill material (named NW) consisted of dolomite particles with a porosity of $20 \%$; its thermal conductivity and specific heat capacity were $2.2 \mathrm{~W} \cdot \mathrm{m}^{-1} \cdot \mathrm{K}^{-1}$ and $860 \mathrm{~kJ} \cdot \mathrm{m}^{-3} \cdot \mathrm{K}^{-1}$, respectively. For the BM-0 model, the groundwater table was set at $20 \mathrm{~m}$ underground and the full borehole was filled with original ground sand. As the borehole was fully saturated below the water table, BM-1 and BM-2 were only added in the section above the water table.

\subsection{Model Building and Meshing}

The simulation software COMSOL Multiphysics was used to establish a single heat exchange borehole model (Figure 7) under the condition of an intermittent operation for one year. The rock mass geometric size was defined as $20 \times 20 \times 150 \mathrm{~m}$ and the material was homogeneous dolomite.
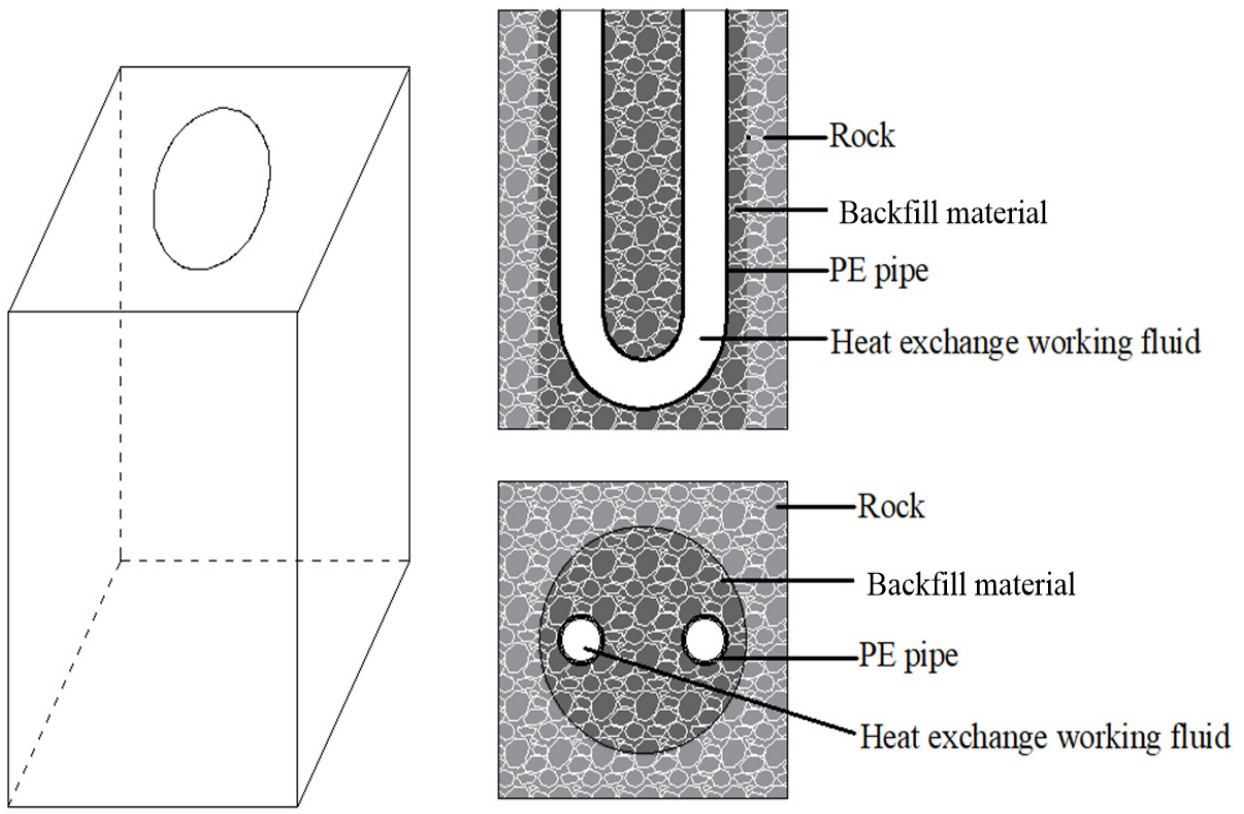

Figure 7. Model structure.

\subsection{Model Definition}

The top surface of the model was considered to be a boundary with no air and water flux. The other boundaries (bottom and side) were set as a constant temperature with a mass heat transfer. The depth of the heat exchange borehole was $120 \mathrm{~m}$. A single U pipe was used with a buried depth of $119 \mathrm{~m}$. The heat carrier in the pipe was water. The above physical parameters or curves of NW, BM- $0, \mathrm{BM}-1$, and BM-2 were input into the model material setting, respectively. The thermofluid model coupled the physical fields of Darcy's law, the porous medium heat transfer, and the pipe flow. The mesh division was ultra-refined (Figure 8), and the basic parameters were shown in Table 4. After 365 days of an intermittent operation, the daily water temperature and the quarterly mean water temperature at the outlet of the U pipe were obtained, as shown in Figure 9 and Table 5, respectively. The setting of NW had no water table and its operation result was used as the reference for comparison. In the models of BM-0, BM-1, and BM-2, the Richards 
Equation was only set in the section of the borehole from the ground surface to $-20 \mathrm{~m}$; Van Genuchten's Equation [30] was adopted to the retention model. With the simulation results, the key heat transfer parameters could be calculated.

The parameters as well as the boundary and initial conditions are shown in Table 4 .

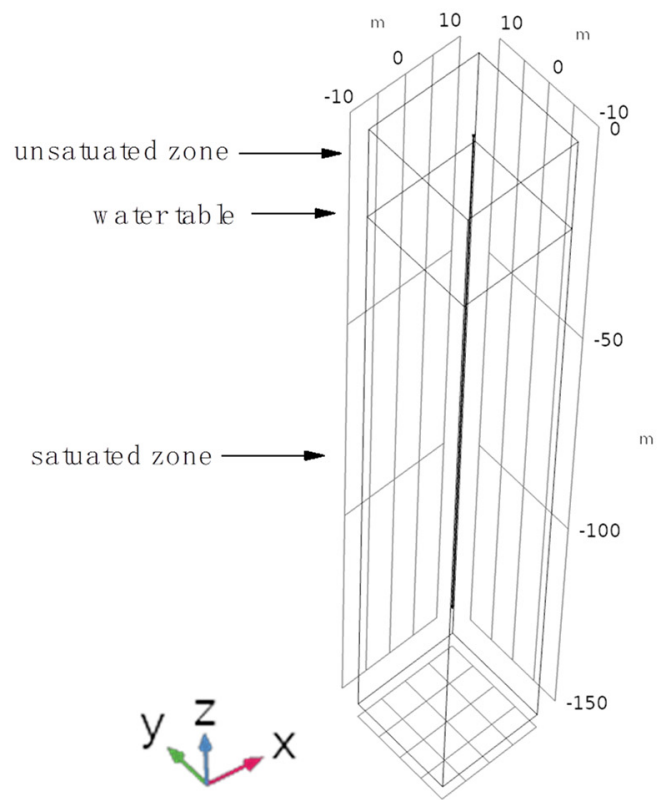

A

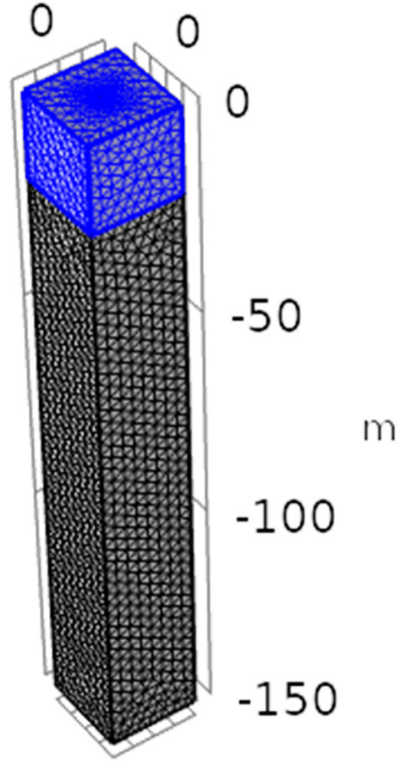

B

Figure 8. Geometric model of numerical simulation (A) Model construction; (B) Meshing.

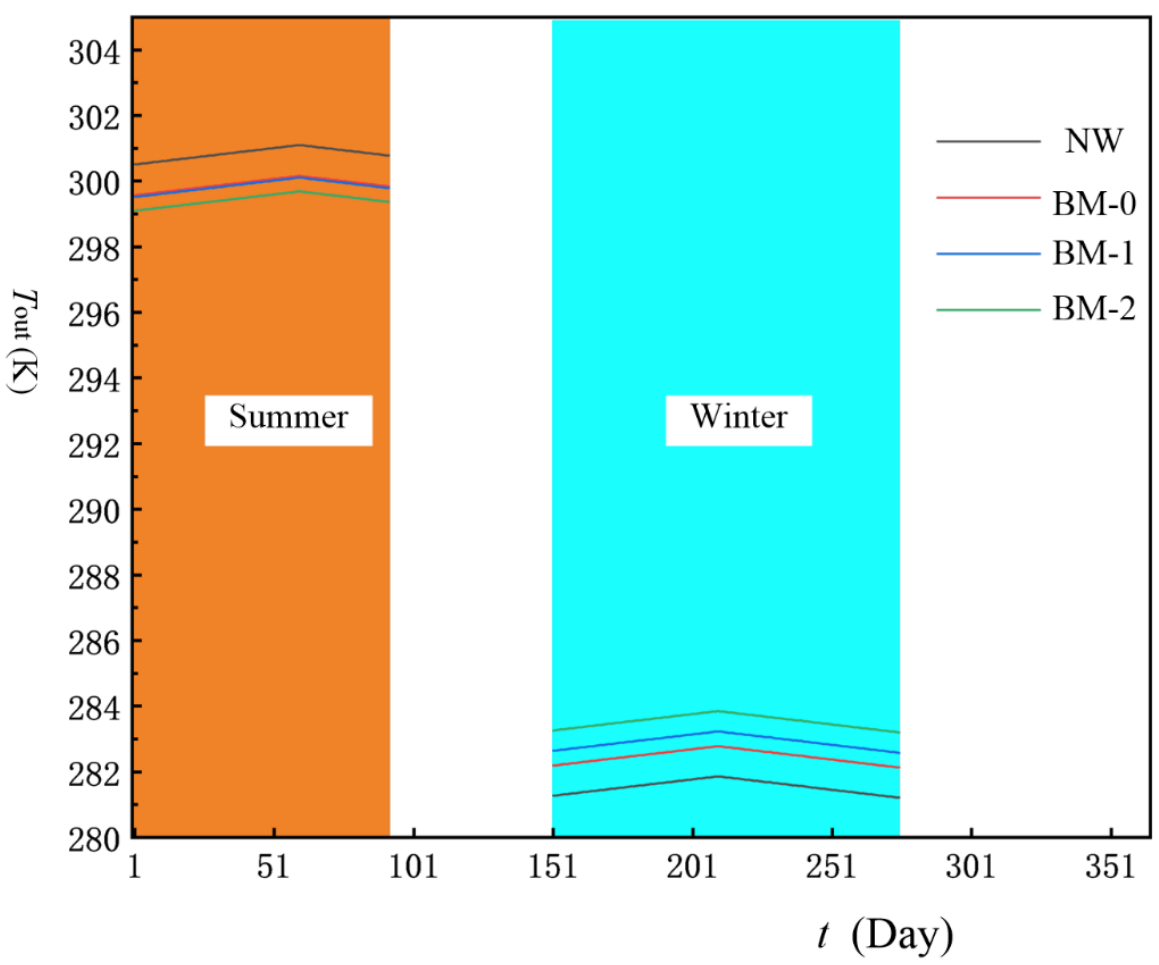

Figure 9. Outlet water temperatures of the U pipe with time. 
Table 4. Parameters of the underground heat exchanger.

\begin{tabular}{ccc}
\hline Parameters & Value & Units \\
\hline Input temperature at shutdown time & 288.15 & $\mathrm{~K}$ \\
Input temperature in summer & 303.15 & $\mathrm{~K}$ \\
Input temperature in winter & 280.15 & $\mathrm{~K}$ \\
Temperature of rock & 289.15 & $\mathrm{~K}$ \\
Temperature of groundwater & 288.15 & $\mathrm{~K}$ \\
Temperature of U pipe & 289.15 & $\mathrm{~K}$ \\
Initial temperature of BM & 289.15 & $\mathrm{~K}$ \\
Outer diameter of U pipe & 3.2 & $\mathrm{~cm}$ \\
Inner diameter of U pipe & 2.6 & $\mathrm{~cm}$ \\
Thickness of U pipe & 3 & $\mathrm{~mm}$ \\
Density of in-pipe fluid & 1000 & $\mathrm{~kg} \cdot \mathrm{m}^{-3}$ \\
Specific heat capacity of in-pipe fluid & 4186 & $\mathrm{~kJ} \cdot \mathrm{m}^{-3} \cdot \mathrm{K}^{-1}$ \\
Velocity of in-pipe medium & 1 & $\mathrm{~m} \cdot \mathrm{s}^{-1}$ \\
Thermal conductivity of U pipe & 0.35 & $\mathrm{~W} \cdot \mathrm{m}^{-1} \cdot \mathrm{K}^{-1}$ \\
Depth of heat exchange borehole & 120 & $\mathrm{~m}$ \\
Buried depth of U pipe & 119 & $\mathrm{~m}$ \\
Diameter of heat exchange borehole & 0.15 & $\mathrm{~m}$ \\
Geometry of rock mass & $0.2 \times 0.2 \times 150$ & $\mathrm{~m}{ }^{3}$ \\
\hline
\end{tabular}

Table 5. Simulation and calculation results.

\begin{tabular}{ccccccc}
\hline Name & $\boldsymbol{T}_{\text {out_}} \mathbf{w}$ & $\boldsymbol{T}_{\text {out_- }}$ & COP & EER & $\boldsymbol{q}$-w & $\boldsymbol{q}$-s \\
\hline NW & 281.54 & 300.86 & 5.275 & 5.289 & 28.704 & 47.289 \\
BM-0 & 282.46 & 299.91 & 5.389 & 5.426 & 42.851 & 60.102 \\
BM-1 & 282.92 & 299.85 & 5.396 & 5.495 & 51.384 & 61.215 \\
BM-2 & 283.53 & 299.43 & 5.446 & 5.587 & 62.699 & 69.006 \\
\hline
\end{tabular}

The piecewise function of the running time was:

$$
\left\{\begin{array}{c}
\text { 0-92 days (June to Aug) summer } \\
\text { 153-275 days (Nov to Feb) winter } \\
\text { Other time shut down }
\end{array}\right.
$$

The control function of the flow fluid rate in the pipe was:

$$
\left\{\begin{array}{cl}
1 \mathrm{~m} / \mathrm{s} & \text { running time } \\
0 & \text { shut down }
\end{array}\right.
$$

The control formulas of Darcy's law were:

$$
\begin{gathered}
\nabla \cdot(\rho u)=\dot{Q}_{m} \\
u=-\frac{\kappa}{\mu}\left(\nabla \rho+\rho g \nabla_{\mathrm{D}}\right) \\
-n \cdot \rho u=0 \text { (no flow area) }
\end{gathered}
$$

The control formula of the pipe heating transfer was:

$$
\rho A C_{\mathrm{p}} u e_{\mathrm{t}} \cdot \nabla_{t} T=\nabla_{\mathrm{t}} \cdot\left(A K \nabla_{\mathrm{t}} T\right)+\frac{1}{2} f_{\mathrm{D}} \frac{\rho A}{d_{\mathrm{h}}}|u| u^{2}+\dot{Q}+\dot{Q}_{\text {wall }}
$$

The control formulas of the porous medium heating transfers were:

$$
\rho C_{p} u \cdot \nabla T_{2}+\nabla \cdot q=\dot{Q}+\dot{Q}_{v d}
$$




$$
q=-k_{\text {eff }} \nabla T_{2}
$$

\subsection{Simulation Result and Analysis}

Figure 9 shows the outlet water temperature of the U pipe when filled with different backfill materials. BM-1 was barely effective in the summer; the addition of BM-2 contributed the most to the temperature difference of the inlet and outlet.

\section{(1) COP and EER calculation}

The refrigeration coefficient of the air conditioner is called the coefficient of performance (COP), which is the ratio of the cooling capacity of the air conditioner to the power consumption. The air-conditioning heating coefficient is the energy efficiency ratio (EER); and Formulas (13) and (14) demonstrate the relationship between the outlet water temperature of a Dimplex SI 30TER+ [31] ground source heat pump system with the COP and EER.

$$
\begin{gathered}
\mathrm{COP}=-0.12 T_{\text {out }}+8.60 \\
\mathrm{EER}=0.15 T_{\text {out }}+4.03
\end{gathered}
$$

where $T_{\text {out }}$ is the water temperature of the outlet in the $\mathrm{U}$ pipe, ${ }^{\circ} \mathrm{C}$.

(2) Calculation of the heat transfer of the borehole heat exchanger

$$
\begin{gathered}
Q_{1}=C_{\mathrm{p}} \cdot m_{1} \cdot\left(t_{\mathrm{s}}-t_{\mathrm{h}}\right) \\
m_{1}=u \cdot A \cdot \rho
\end{gathered}
$$

where $Q_{1}$ is the heat transfer capacity, $\mathrm{W} ; C_{\mathrm{P}}$ is the specific heat capacity of the water, taken as $4200 \mathrm{~J} \cdot \mathrm{kg}^{-1} \cdot \mathrm{k}^{-1} ; m_{1}$ is the flow rate of the circulating water, taken as $0.53 \mathrm{~kg} \cdot \mathrm{s}^{-1} ; t_{\mathrm{s}}$ is the water temperature at the inlet of the $\mathrm{U}$ pipe, $\mathrm{K}$; and $t_{\mathrm{h}}$ is the average temperature of the water at the outlet of the buried pipe when the unit is running smoothly, $\mathrm{K}$.

\section{(3) Calculation of the heat transfer per meter}

The heat transfer rate per meter is related to the depth of the well, the physical parameters of the circulating fluid in the pipe, the velocity of the circulating fluid, and the inlet and outlet temperature. According to Formula (17), the heat transfer rate per meter is the ratio of the heat transfer amount of fluid in the tube to the depth of the heat exchange borehole:

$$
q=\frac{Q_{1}}{L}
$$

where $q$ is the heat transfer rate per meter, $\mathrm{W} / \mathrm{m} ; Q_{1}$ is the heat exchange rate of the borehole, $\mathrm{W}$; and $L$ is the depth of the heat exchange borehole, $\mathrm{m}$.

The calculated values of the COP, EER, and heat transfer rate per meter $(q)$ are summarized in Table 5.

\section{Discussion}

From the experiment presented in Section 3, it was known that the 3A-MS enhanced the loose porous structure and adsorption capacity of the material, and in turn improved the surface tension between the water and solid, hence microcosmically increasing the height of the water column in the capillary and macroscopically increasing the water saturation in the soil. The BM was a three-phase medium and the addition of a 3A-MS led to an increase in the proportion of the liquid phase, displacing a part of the air and solid in the pores. The overall specific heat capacity of the material improved because of the higher specific heat capacity of the water. However, as the thermal conductivity of static water is lower, the effective thermal conductivity and thermal diffusivity of the materials decreased when a 3A-MS was added.

The simulation work demonstrated that the higher the amount of the 3A-MS added, the higher the heat transfer rate per meter. The higher heat capacity of the backfill material 
delayed a temperature variation in the borehole. This maintained the inlet and outlet temperature difference, which was beneficial to the heat exchange. A higher heat transfer rate per meter undoubtedly can reduce the total drilling length and costs as well as improve the engineering efficiency. Compared with NW, the COP of BM- $0, \mathrm{BM}-1$, and BM-2 increased 2.2\%, 2.3\%, and 3.2\%, respectively, and the EER increased $2.6 \%, 3.9 \%$, and $5.6 \%$, respectively.

The section of the borehole near the surface was the main part where the thermal short-circuit of the $U$ pipes occurred, which reduced its heat exchange capacity. Due to the addition of a 3A-MS, the specific heat capacity was improved and the phenomenon of a thermal short-circuit was alleviated. In addition, a molecular sieve is an inexpensive material that only needs $10 \mathrm{CNY} / \mathrm{kg}(1.6 \mathrm{USD} / \mathrm{kg})$, which increases the cost to 125-250 CNY (20-40 USD) per hole according to the addition of $5 \%$ to $10 \%$ above but the total drilling length and costs are reduced. On the whole, a 3A-MS is an effective additive that can reduce construction costs and improve economic benefits.

\section{Conclusions}

By adding $0 \%, 5 \%$, and $10 \%$ of a $3 \mathrm{~A}-\mathrm{MS}$ into BM, the specific heat capacity of the material improved with the raising of the water content but the growth was different. Compared with BM-0, the specific heat capacity of BM-2 could be heightened by $12.4 \%$ whereas that of BM-1 had no obvious change. The average thermal conductivity of BM-1 and BM-2 declined by $10.5 \%$ and $26.3 \%$, respectively, and the average thermal diffusivities of BM-1 and BM-2 fell by $10.2 \%$ and $35.0 \%$, correspondingly. Excess water was adsorbed in the porous structure of the 3A-MS during backfilling, which ensured that the heat and water were locked in the heat exchange borehole and the heat storage capacity of the BM was elevated to a certain extent. However, the water adsorbed by the 3A-MS had a low thermal conductivity and the effective thermal conductivity and thermal diffusivity of the composite materials were reduced. As a result, the ability of the material itself to spread heat outward descended.

Both the COP and EER of the GSHP were enhanced due to the infiltration of the groundwater from the results of the numerical simulation and calculation analysis. The heat transfer rater per meter of BM-0, BM-1, and BM-2 in summer were $27.1 \%, 29.4 \%$, and $45.9 \%$ higher than that of NW, respectively; those in winter were $49.3 \%, 79.0 \%$, and $118.4 \%$ higher than that of NW, respectively.

It is suggested that the porosity of BM should be reduced to overcome the negative effect of a low thermal conductivity of air whilst adding an active agent to improve the water content and heat storage capacity.

Author Contributions: Conceptual formation, laboratory test and writing, T.L.; resource management and review, P.P.; laboratory test Y.C.; numerical simulation, D.H.; writing and revise, C.W. All authors have read and agreed to the published version of the manuscript.

Funding: This work was supported by the National Natural Science Foundation of China (Grant Number: 52066005), the Natural Science Foundation of Guizhou Province (Grant Number: [2020]2Y025), and the Postgraduate Education Innovation Program in Guizhou Province (Grant Number: YJSKYJJ[2021]043).

Institutional Review Board Statement: Review board has reviewed the manuscript and confirmed. Informed Consent Statement: All authors have been informed and agreed to publish.

Data Availability Statement: All data are available in the manuscript.

Conflicts of Interest: The authors declare no conflict of interest. 


\begin{tabular}{|c|c|}
\hline \multicolumn{2}{|c|}{ Nomenclature Symbols and Abbreviation } \\
\hline Nomenclature Symbols & Experission \\
\hline$\rho$ & Density $\left(\mathrm{kg} / \mathrm{m}^{3}\right)$ \\
\hline$\mu$ & Dynamic viscosity $(\mathrm{Pa} \cdot \mathrm{s})$ \\
\hline$\kappa$ & Permeability $\left(\mathrm{m}^{2}\right)$ \\
\hline g & Acceleration of gravity $\left(\mathrm{m}^{2} / \mathrm{s}\right)$ \\
\hline$A$ & Pipe cross-section area $\left(\mathrm{m}^{2}\right)$ \\
\hline$C_{\mathrm{p}}$ & Heat capacity at a constant pressure $(\mathrm{J} / \mathrm{kg} \cdot \mathrm{K})$ \\
\hline$T^{r}$ & Temperature (K) \\
\hline$v$ & Velocity $(\mathrm{m} / \mathrm{s})$ \\
\hline$k$ & Thermal conductivity $(\mathrm{W} /(\mathrm{m} \cdot \mathrm{K}))$ \\
\hline$\dot{Q}$ & General heat source $\left(\mathrm{W} / \mathrm{m}^{3}\right)$ \\
\hline$\dot{Q}_{\text {wall }}$ & External heat exchange through the pipe wall $(\mathrm{W} / \mathrm{m})$ \\
\hline $\mathrm{q}$ & Conductive heat flux $\left(\mathrm{W} / \mathrm{m}^{2}\right)$ \\
\hline$d_{\mathrm{h}}$ & Inner diameter of the $U$ pipe $(\mathrm{cm})$ \\
\hline$k_{\text {eff }}$ & Effective thermal conductivity $(\mathrm{W} /(\mathrm{m} \cdot \mathrm{K}))$ \\
\hline$D$ & Thermal diffusivity $\left(\mathrm{m}^{2} / \mathrm{s}\right)$ \\
\hline$Q_{\mathrm{vd}}$ & Heat transfer of viscous dissipation $\left(\mathrm{W} / \mathrm{m}^{3}\right)$ \\
\hline$T_{\text {in }}$ & Inlet water temperature of $U$ pipe $(K)$ \\
\hline$T_{\text {out }}$ & Outlet water temperature of U pipe (K) \\
\hline$T_{0}$ & Initial temperature $(\mathrm{K})$ \\
\hline$T_{\text {out_w }}$ & Mean outlet temperature in winter (K) \\
\hline Tout_s & Mean outlet temperature in summer $(\mathrm{K})$ \\
\hline$q-\mathrm{s}$ & Heat transfer rate per meter in summer $(\mathrm{W} / \mathrm{m})$ \\
\hline$q-\mathrm{w}$ & Heat transfer rate per meter in winter $(\mathrm{W} / \mathrm{m})$ \\
\hline \multicolumn{2}{|l|}{ Abbreviation } \\
\hline $\mathrm{BM}$ & Backfill material \\
\hline 3A-MS & 3A molecular sieve \\
\hline GSHP & Ground source heat pump \\
\hline GSHPs & Ground source heat pump system \\
\hline COP & Coefficient of performance \\
\hline EER & Energy efficiency ratio \\
\hline SWCC & Soil-water characteristic curve \\
\hline SEM & Scanning electron microscope \\
\hline EDS & Energy dispersive spectrometer \\
\hline
\end{tabular}

\section{References}

1. Song, X. Evalutaion on utilization potential of shallow geothermal energy in major cities of Guizhou. Casologica Sin. 2018, 37, 9-16.

2. Yi, L.; Qi, J.; Li, X.; Xu, M.; Zhang, X.; Zhang, Q. Geochemical characteristics and genesis of the high-temperature geothermal systems in the north section of the Sanjiang Orogenic belt in southeast Tibetan Plateau. J. Volcanol. Geotherm. Res. 2021, 414, 107244. [CrossRef]

3. Zhou, W.; Pei, P.; Hao, D.Y.; Wang, C. A numerical study on the performance of ground Heat Exchanger Buried in Fractured Rock Bodies. Energies 2020, 13, 1647. [CrossRef]

4. Khosravi, N.; Abdolmohammadi, H.R.; Bagheri, S.; Miveh, M.R. Improvement of harmonic conditions in the AC/DC microgrids with the presence of filter compensation modules. Renew. Sustain. Energy Rev. 2021, 143, 110898. [CrossRef]

5. Kong, D.; Wan, R.; Chen, J.; Kang, J.; Jiao, X. Effect of gradation on the thermal conductivities of backfill materials of ground source heat pump based on loess and iron tailings. Appl. Therm. Eng. 2020, 180, 366-376. [CrossRef]

6. Agrawal, K.K.; Misra, R.; Agrawal, G.D. Thermal performance analysis of slinky-coil ground-air heat exchanger system with sand-bentonite as backfilling material. Energy Build. 2019, 202, 109351. [CrossRef]

7. Rong, W.; Kong, D.; Kang, J.; Yin, T.; Ning, J.; Ma, J. The experimental study on thermal conductivity of backfill material of ground source heat pump based on iron tailings. Energy Build. 2018, 174, 1-12. [CrossRef]

8. Delaleuxab, F.; Antoine, O.; Dominguez, B. Enhancement of geothermal borehole heat exchangers performances by improvement of bentonite grouts conductivity. Appl. Therm. Eng. 2012, 33-34, 92-99. [CrossRef]

9. Zhang, X.; Zhao, M.; Liu, L.; Huan, C.; Zhao, Y.; Qi, C.; Song, K. Numerical simulation on heat storage performance of backfill body based on tube-in-tube heat exchanger. Constr. Build. Mater. 2020, 265, 120340. [CrossRef] 
10. Yang, W.; Yang, J. Effect of the Mixture Ratio of the Phase Change Backfilled Material on the Energy Storage and Heat Transfer Characteristics of Ground Heat Exchange. Build. Energy Effic. 2020, 48, 50-56.

11. Li, X.; Tong, C.; Lin, D.; Liu, L. Research on U-tube Heat Exchanger with Shape-stabilized Phase Change Backfill Material. Procedia Eng. 2016, 146, 640-647. [CrossRef]

12. Ban, H.; Roh, S.; Park, W.-J. Performance evaluation of buried concrete pipe considering soil pressure and crack propagation using 3D finite element analysis. Appl. Sci. 2021, 11, 3292. [CrossRef]

13. Gluchowski, A.; Sadzevicius, R.; Skominas, R.; Sas, W. Compacted anthropogenic materials as backfill for buried Pipes. Materials 2021, 14, 717. [CrossRef] [PubMed]

14. Yoon, S.; Kim, G.-Y. Measuring thermal conductivity and water suction for variably saturated bentonite. Nucl. Eng. Technol. 2021 53, 1041-1048. [CrossRef]

15. Zhang, X.; Xu, M.; Liu, L.; Huan, C.; Zhao, Y.; Qi, C. Experimental study on thermal and mechanical properties of cemented paste backfill with phase change material. J. Mater. Res. Technol. 2020, 9, 2164-2175. [CrossRef]

16. Wang, E.; Zhang, F.; Zhang, Y.; Zhao, Q. Influence investigation of thermal load imbalance on geothermal. Procedia Eng. 2017, 205, 3846-3851. [CrossRef]

17. You, T.; Li, X.; Cao, S.; Yang, H. Soil thermal imbalance of ground source heat pump systems with spiral-coil energy pile groups under seepage conditions and various influential factors. Energy Convers. Manag. 2018, 178, 123-136. [CrossRef]

18. Wang, B.; Zhu, Y.; Qin, Q.; Liu, H.X.; Zhu, J. Development on hydrophobic modification of aluminosilicate and titanosilicate zeolite molecular sieves. Appl. Catal. A 2021, 611, 117952. [CrossRef]

19. Jiao, C.; Jiang, H.; Chen, X. Reutilization of abandoned molecular sieve as flame retardant and smoke suppressant for thermoplastic polyurethane elastomer. J. Therm. Anal. Calorim. 2019, 138, 3905-3913. [CrossRef]

20. Jiao, C.; Jiang, H.; Chen, X. Properties of fire agent integrated with molecular sieve and tetrafluoroborate ionic liquid in thermoplastic polyurethane elastomer. Polym. Adv. Technol. 2019, 30, 2159-2167. [CrossRef]

21. Luo, T.; Jiao, C.; Chen, X.; Jiang, H. Flame-retardant effect of modified molecular sieve by ionic liquid in TPU. J. Therm. Anal. Calorim. 2022, 147, 4141-4150. [CrossRef]

22. Wang, M.; Wang, S. Concerns of developing geothermal resources in Guizhou province and countermeasure proposals. Guizhou Geol. 2007, 1, 9-12.

23. Available online: http:/ / bzdt.ch.mnr.gov.cn/browse.html?picId=\%274o28b0625501ad13015501ad2bfc0291\%27 (accessed on 10 January 2022).

24. Feddes, R.A.; Kabat, P.; van Bakel, P.J.T.; Bronswijk, J.J.; Halbertsma, J. Modeling soil water dynamics in the unsaturated zone-State of the art. Hydrogeol. J. 1988, 100, 69-111. [CrossRef]

25. Sophocleous, M. Understanding and explaining surface tension and capillarity: An introduction to fundamental physics for water professionals. Hydrogeol. J. 2010, 18, 811-821. [CrossRef]

26. Nam, S.; Gutierrez, M.; Diplas, P.; Petrie, J.; Wayllace, A.; Ning, L. Comparison of testing techniques and models for establishing the SWCC of riverbank soils. Eng. Geol. 2010, 110,1-10. [CrossRef]

27. Wu, J.; Yuan, J.; Yang, S. Experimental study on SWCC of expansive soil with cracks using filter paper method. Adv. Sci. Technol. Water Resour. 2013, 33, 61-64.

28. Gori, F.; Corasaniti, S. New model to evaluate the effective thermal conductivity of three-phase soils. Int. Commun. Heat Mass Transfer. 2013, 47, 1-6. [CrossRef]

29. Lei, Z.; Yang, S.; Xie, S. Soil Hydrodynamics; Tsinghua University Press: Beijing, China, 1988.

30. van Genuchten, M.T. A closed-form equation for predicting the hydraulic conductivity of unsaturated soils. Soil Sci. Soc. Am. J. 1980, 44, 892-898. [CrossRef]

31. Hein, P.; Kolditz, O.; Gorke, U.J.; Bucher, A.; Shao, H. A numerical study on the sustainability and efficiency of borehole heat exchanger coupled ground source heat pump systems. Appl. Therm. Eng. 2016, 100, 421-433. [CrossRef] 